\title{
PEDULI EKOLOGI ALA FRANSISKUS ASISI
}

\author{
Surip:Stanislaus: \\ Program Studi Ilmu Filsafat, Fakultas Filsafat, Unika Santo Thomas \\ Email: suripofmcapalyahoo.com
}

\begin{abstract}
Abstrak
Kepedulian Fransiskus terhadap sesama manusia, sesama makhluk ciplaan dan lingkungan alam berakar pada relasinya dengan Allah Pencipta la melihat dirànya, segala makhluk dari lingkurigarı alam sebagai sama-sama atau sesama ciptaan yang berasal dari satu asal, yaitu Allah Pencipta semesta alam. Oleh karena itu, semua makhluk ciptaan dipandang, diperlakukan dan dirintainya sebagai saudara dan saudlari. Mengapa Fransiskus bersikap demikian? Ia memandang alam semesta tan segala isinya bukan terutama dari segi kegunaannya demi pemenuhan kebutuhan dan peningkatan mutu hidup manusia, tetapi lebih pada nilai yang ada dalam đirinya sendiri dan arti simbolis sakramentalnya. Keberadaan setiap makhluk bukan saja karena bermanfaât bagi manusia, tetapi juga karena memilikí nilai dalam dirinya sendiri dan menjadi tanda yang menghadirkan Allah, Setiap maklluk pun memiliki kesamaan, yakni sama-sama sebagai ciptaan Allah, sehingga semuanya sederajat dan Fransiskus menyapanya dengan sebutan saudarasaudari. Madah Gita Sang Surya yang digubah dua bulan menjelang kemattannya, menyingkapkan kedekatan yang begitu mendalam Fransiskus dengan alam dan segala makhluk ciptaan.
\end{abstract}

Kata-kata kunci : peduli, sesama, ciptaan, Pencipta, samdara, satrdari, munfaat, nilni, sak ramental, kébcradnän, kedekatün.

\section{Pengantar}

Pada tgl. 29 November 1979 Bapa Paus Yohanes Paufus II menetapkan St. Fransiskus Asisi (1181-1226) sebagai Pelindung Pelestarian Lingkungan Hidup atas permintaan dari Organisasi Internasional Planning Environmental and Ecological Instinte for Quality of Life. Dasarnya adalah keintiman relasi Fransiskus yāng sangat istimewa dengan alam semesta. Dengan rendah hati ia menyadari bahwa dirinya sebagai manusia hanyalah bagian kecil dari keseluruhan surga

\footnotetext{
- Surip Stanislaus, lisensiat dulam bidang Theulogi, lulusim Universitas Gregoriana, Ruma; dosẹn Kitalo Suci pada Fakultas Filsafai Inika St. Thumas; Sumatera Ltara.
} 
dan bumi, Khalik dan makhluk, Pencipta dan alam ciptaan-Nya. Oleh karena itu, berhadapan dengan makhluk ciptaan lainnya ia tidak menempatkan diri di atas tetapi memandangnya sebagai partner atau rekan yang dengannya bersama-sama memuji Tuhan, Allah Pencipta semesta alam dan segala isinya.'

\section{Bersaudara dengan Semua Ciptaan}

Rotzetter melukiskan Fransiskus sebagà pribadi yang bersaudara dengan semua makhluk ciptaan. Dalam kisah legendaris pertemuannya dengan serigala di Gubio terungkap makna perdamaian, yang juga membuat kelinci tidak lagi merasa malu, keluarga burung mendengarkannya dan masyarakat mengenal baik Fransiskus. Pertemuan dengan Fransiskus membuat makliluk oiptaan lainnya menemukan keberadaan dirinya dan mengembangkan kehidupan baru. ${ }^{2}$ Bonaventura menulis persahabatan Fransiskus dengan sesama makhluk ciptaan Allah itu sbb: $:^{3}$

Setiap menyadari asal dari segala makhluk maka Fransiskus dipenuhi dengan takwa yang berlimpah-limpah. Makhluk-makhluk betapa pun kecilinya disebutnya dengan nama saudara atau saudari. justru karena setahumya mereka mempumyai satu asal seperti dirinya sendiri Namun makhluk-maklnluk yang karena kesamaan alamiah menunjuk pada kelembutan lati Kristus dan mengungkapkan lambang dalam Kitab Suci disayanginya dengan lebih mesra dan lembut hati. Berulang kali ditebusnya anak domba yang dibawa orang ke pembantaian, karena ia ingal akan Anak Domba Allah yang lemah lembut dan dibawa ke pembantaian untuk menelus para pendosa.

Sekali peristiwa hamba Allah itu bermalam di biara St. Verekundus, Keuskupan Gubbio. Pada malam itu seekor domba melahirkan anaknya. Seeker babi betina ganas yang tidak menyayangkan

\footnotetext{
I N.S. Dister. "Santo I'zansiskus asisi dan Habungannza dengan Perhatan Modern untuk.

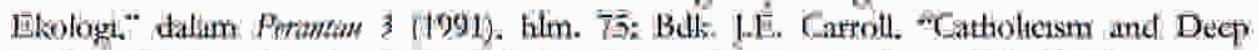

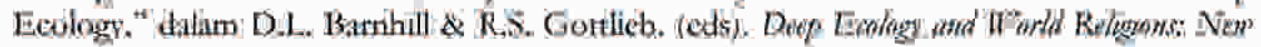

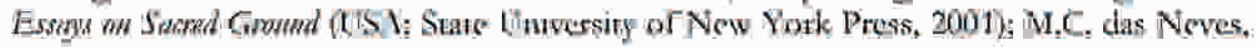

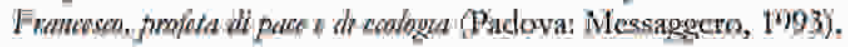

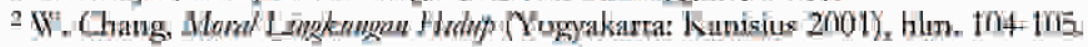

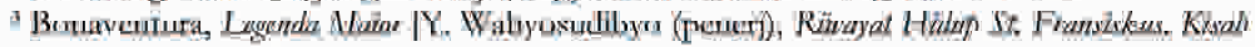

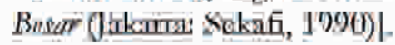


nyawa anak domba tak bersalah itu menggigitnya hingga matiMendengar hal itu Fransiskus yang penuh kasith sayang sangat terharu karena ingat akan Anak Domba Allah tak bemoda dan meratapinya di depan semua orang. katanya: "Ah kasihum saudaruku anak domba kecill. hewan rak hensalah yang melamhangkan Krisnis. Terkutuklah babi betina jahat yang telah membunub engkau. Tiduk ada orang atau hewan satu pum akan memakan dagingnya."

Aneh bin ajail. Sègera babi keparat itu sakit, tiga hari lämanya menderita sakit hebat dan akhirnya mati sebagai balasan. Lalu bangkainya dibuang dekal tembok biara dan lama terletak di situ dan menjadi kering seperti papan, tidak ada binatang satu pun yang mau memakannya. Biarlah kelaliman manusia mendapat peringatan karenanya, yaitu hukuman akan dikenakan karena keganasan binatang saja dihukum dengan kematian yang mengerikan. Tetapi sebaliknya hendaknya orang beriman yang salelı merenungkan, betapa kuat dan ạjaib dan terasa sedapnya kasih sayang hamba Allah sampai makhluk yang tak berakal pun betterima kasih menanggapinya dengan caranya senditi.

Ketika Fransiskus mengadakan perjalanan lagi, di dekat kota Siena didapatinya kawanan besar domba-domba di rerumputan. Seperti lazimnya ia memberi salam dengan ramah tamah dan segera mereka berhenti merumput lalu semua berlari-lari kepadanya sambil mengangkat kepalanya. Mereka menyambutnya begitu rupa sehingga gembalagembala keheran-heranan melihat semua domba dan anak domba balikan bandot melonjak-lonjak dengan riang di sekelilingnya.

Pada kesempatan lain hamba Allah itu berada di dekat gereja St. Maria Portiuncula ketika seekor domba dipersembahkan orang kepadanya. Karena cintanya akan ketidaksalahan dan kesederhanaan yang menjadi sifat alamiah domba, domba iru diterimanya dengan senang hati dan rasa terimakasil. Pria yang takwa itu menasihati agar domba itu mengindahkan ibadat ilahi tanpa mengganggu saudara-saudaranya. Domba itu pun seakan-akan mengerti nasihat baik hamba Allah itu đan memelihara dengan seksama pesannya. Sebab segera domba itu mendengar para saudara menyanyi kōor. ia pun masuk kè gereja dan tanpa diberitahu siapa pun jua berlutu dan mengembik di depan altar Santa Perawan. Bunda Anak Domba Allah, seakan-akan hendak memberi 
salam kepadanya. Dan lagi, bila Tubuh Mahakudus Kristus diangkat di tengah-tengah perayaan Misa, domba itu berlutut sambil menundukkan kepalanya, seakan-akan dengan sikap hormatnya hendak menegur kekurangan hormat mereka yang kurang bakti dan mengajak orang-orang yang berbakti kepada Kristus untuk semakin menghormati Sakramen Mahakudus.

Sewaktu tinggal di Rona pun karena hormatnya akan Anak Domba Allah yang lemah lembut Fransiskus memelihara seekor domba. Ketika ía mă berangkat lagi dari kota itu, maka anak domba itu diserahkan kepada seorang wanita hangsawan, nyonya Yakoba de Settisoli, untuk memeliharanya. Anak domba itu seakan-akan sudah dilatih oleh Fransiskus di bidang kerobanian. Anak domba itu menjadi teman yang tak terpisahkan, mengikuti nyonyanya kalau pergi ke gereja. berada di sana dan kembali dari sana. Jika nyonyanya terlambat bangun, anak domba itu berdiri pada kaki belakangnya dan mendesak-desak dengan tanduknya dan membangunkan nyonyanya dengan embikannyă, dan dengan sikap serta gerak-geriknya mendorongnya untuk lekas-lekas pergi ke gereja. Karena anak domba itu menjadi murid Fransiskus, maka pada gilirannya juga menjadi guru kesalehan, sehingga nyonya itu memeliharanya sebagai hewan piaraan yang ajaib dan patut disayang.

Pada kesempatan lain lagi ketika Fransiskus linggal di pertapaan Greccio, penduduk di tempat itu tertimpa berbagai kemalangan, sebab segerombolan serigala yang rakus tidak hanya memakan ternak tetapi juga manusia. Dan lagi hujan es tahunan dengan badai pun merusak ladang-ladang dan kebun-kebun anggur mereka. Nah, bentara Injiil suoi itu berkotbah kepada mereka katanya:

-Demi kemuliaan dan pujian bagi Allah Yang Mahakuasa aku menjamin kalian, bahwa segala malapetaka akan lenyap dan Tuhan dalam kerelaanNya akan memperkaya kalian dengan barang-barang jasmani, jika kalian percaya kepadaku. Ratapilah dirimu sendiri dan setelah mengaku dosa dengan sungguh-sungguh hasilkanlah buah yang sesuai dengan pertobatan (Maı 3:8). Sekali lagi kuwartakan kepada kalian, jika kalian tidak tahu betterimakasih atas anugerah-anugerah dan berbalik kembali ke muntahmu, maka malapetaka akan ditimpakan lagi atas diri kalian dan 
hukuman pun akan dilipatgandakan dan murka Allab yang lebih besar akan mengamuk kalian."

Karena orang-orang mendengarkan nasihatnya dan melakukan pertobatan. makà sejak hari itu makapetaka lenyap, marabahaya hilang dan serigala mupun hujan es tidak mengganggu mereka lagi. Bahkan lebih hebat lagi, jika ladang-ladang dari daerah tetangga-tetangga mereka dilintasi hujan es dan hujan itu mendekati daerah mereka, maka hujan es berhenti di perbatasan atau membelok ke jurusan lain. Hujan es dan serigala-serigala menepati janji hamba Allah, tidak berani melawan hukum takwa dan tidak mau merugikan lagi orang-orang yang telah bertobat untuk hidup takwa, selama mereka menaati perjanjian itu dan tidak melanggar hukum Allah. Oleh karena itu, hendaknya kita memandang baik takwa pria yang berbahagia itu, yang begitu ajaib kemurahan hati dan kekuatannya, sehingga ia menjinakkan binatangbinatang liar, membiasakan binatang-binatan hutan bersahabat dengannya, melatih hewan-hewan jinak dan membual makhluk-makhluk tak berakal yang memberontak kepada manusia sejak kejatuhannya ke dalam dosa dapat mematuhi manusia lagi. Sungguh sikap takwa itulah yang telah mempersatukan segala makhluk dengan dirinya dan menjanjikan harapan baru bagi kehidupan di bumi ini sekarang dan yang akan datang.

(Legenda Maior VIH, 6-7.II)

Kisali-kisah yang tercatat dalam IC elano XXI. 58.60-6I; XXVIII, 77-79; XXIX, 80 dan Fioretti 22 pun mengungkapkan persahabatan mendalam dan penghargaan Fransiskus yang tinggi terhadap sesama makhluk hidup ciptaan Tuhan bahkan yang tidak berakal budi sekali pun. Fransiskus membuka diri dan hati terhadap segala makhluk dan keterbukaan itu adalah keterbukaan yang bersahabat dan membangun, keterbukaan yang tidak melecthkan dan tak merusak. keterbukaan yang meneiptakan persahabatan timbal-balik. Kisah populer dalam Fioretti 21 berikut mengungkapkan nilai persahabatan Fransiskus tersebut.

Sewaktu Fransisku di kota Gubbio, seekor serigala yang amat besar berkeliaran di daerah sekkitarnya. Serigala itu mengerikan dan ganas. la tidak hanya memangsa binatang-binatang tetapi juga manusia. 
Semua penduduk kota hidup dalam ketakutan karena serigala itu sering mendekati kota. Setiap orang yang bepergian ke luar kota membawa senjata, namun tak seorang pun sanggup melindungi dirinya bila melawan binatang itu sendirian. Rasa takut memuncak sedemikian rupa sehingga tak seorang pun berani meninggalkan kota.

Fransiskus-amat kasihan akan orang-orang di tempat itu. Ta ingin menemui serigala itu, tetapi semua rakyat kota mencegalmya. Fransiskus membual tanda salib lalu pergi ke daerah itu bersama sahabal-sahabamya dengan menaruh kepercayaan sepenuh-penuhnyà pada Allah. Ketika yang lainnya tidak mau pergi lebih joub, Fransiskus berjalan terus menuju tempat serigala tinggal. Ketika serrigala itu melihat rombongan penghuni kota yang keluar untuk melihat mukjizat itu, maka ia pun menyerbu ke arah Fransiskus dengan cakar terbuka. Ketika serigala mendekal. Fransiskus membuat tanda salib di atasnya dan menyapanya: "Kemarilah" Sandara Serigala. Demi nama Kristus aku memerintahkan kepadamu jangan menyerang aku atau laümya." Aneh, begitu Fransiskus membuat tanda salib, serigala ganas itu memasukkan cakar-cakarnya kembali. la menati perintah Fransiskus dan membaringkan diri dengan lembut di kaki Fransiskus seperti seekor anak domba. Kemudian berkatalah Fransiskus kepadanya;

"Saudara Serigala, engkau sangat menyusahkan daerah ini dan melakukan kejahatan besar dengan menghaneurkan dan menghabiskan nyawa makhluk-makhluk Allah tanpa alasm. Engkau tidak saja membunuhi dan memakan binatang-binatang. tetapi juga berani membunuh dan menelan manusia yang diejptakan Allab menurut citraNya. Karena itu engkau pantas digantung sebagai perampok dan pembunuh yang keji. Seluruh rakyat berteriak mengaduh melawan engkau dan seluruh daerah ini membencimu. Akan tetapi kini aku ingin mengadakan perdamaian antara engkau dan mereka, dan bila engkau tidak melakukan kejahatan lagi terhadap mereka, maka mereka akan melupakan kejahatan masa lampaumu dan tak seorang manusia atau seekor anjing pun akan memburu-buru engkau lagi."

Serigala itu menggerak-gerakkan tubuh, ekor dan mata serta menundukkan kepalanya, memperlihatkan bahwa ia menerima anjuran Fransiskus dan bersedia menaatimya. Berkatalah Fransiskus: 
"Saudara Serigala, karena engkau bersedia membuat perjanjian ini dan memeliharanya. aku menjamin bahwa makananmu akan disediakan secara teratur oleh penduduk daerah ini selama hidupmu agar engkau tidak kelaparan sebab aku tahu baliwa engkau melakukan kejahatan ini karena lapar. Atas kemurahan yang kuperoleh untukmu, aku ingin agar engkau berjanji kēpadaku bahwa engkau tak akan melukai manusia atau hewan lagi Mankah engkau herjanji demikian?*

Serigala itu menundukkan kepalanya, memperlihatkan dengan jelas bahwa ia berjanji. Fransiskus berkata: "Saudara Serigala aku ingin agar engkau memberikan jaminan kepadaku bahwa engkau akan setia pada janji inj karena tanpa jaminan in aku tak dapat mempercayai engkau." Ketika Ftansiskus mengulurkan tangan untuk menerima jaminan itu, serigala itu mengangkat kaki depannya dan menempatkannya dengan lembut dalam tangan Fransiskus sebagai bukti kesetiaannya.

Kata Fransiskus selanjutnya: "Saudara Serigala. demi nama Yesus Kristus, aku perintahkan kepadamu ikutlah aku! Percayalah kepadaku. kita pergi mengesahkan ini demi nama Allah." Serigala itu pun dengan taat mengikuti Fransiskus selembut seckor domba. Penghuni kota menyaksikan hal itu dengan membisu. Segera berita itu tersiar di daerah-daerah sekitarnya. Maka seluruh rakyat, tua-muda dan anak-anak, pria dan wanita bergegas-gegas ke lapangan kota untuk melihat serigala bersama Fransiskus.

Ketika seluruh rakyat berkumpul di sana, Fransiskus hangkiı dan berkotbah kepada mereka, menyatakan kepada mereka antara lain bahwa karena dosa-dosalah maka Allah membiarkan terjadinya malapetaka demikian. Kata Fransiskus:

"Kobaran nyala neraka yang akan dirasakan selama-lamanya oleh orang yang dikutuk lẻbil mengerikan dări pada taring-taring šcrigăla yāng tidak dapat berbuat lebih dari pada mengliancurkan tubuh. Bukankah orang harus lebili takut akan cakar-cakar neraka dari pada terliađap binatang kecil ini? Karena itu Saudara-saudara terkasih, kembalilah kepada Allah, lakukanlah tapa yang tepat untuk dosā-dosāmu dan Allah akan membebaskan kamu dari serigala kehidupan, dan dari api neraka dalam 
kehidupan nanti. Dengarlah Saudara-saudaraku, Saudara Serigala yang kini berdiri di depanmu telah berjanji dan memberikan jaminan tidak akan mengganggu kamu lagi jika kamu berjanji menyediakan makanan yang dibutuhkannya setiap hari. Saya jamin bahwa ia akan menaati ini dengan setia."

Semua penduduk itu dengan suara bulat berjanji akan memberi makan serigala itu setiap hari. Kemudian Fransiskus berkata kepada serigala itu di depan semua penduduk: "Saudara Serigala, herjanjilah engkau akan memelihara perjanjian damai dengan mereka dan tidak akan melukai seorang manusia, hewan atau makhluk lainmya?" Serigala itu berlutut dan menundukkan kepalanya dan dengan gerakan-gerakan lembut tubuh, ekor dan telinganya, memperlihatkan sedapat-dapatnya bahwa ia bersedia memelihara perjanjian damai dengan mereka. Lalu Fransiskus berkata: "Saudara Serigala, di luar gerbang kota tadi engkau memberikan jaminan kepadaku untuk memelihara janji ini kini aka menghendakf agar engkau memberikan jamünan ini kepadaku di depan semua arang, bahwa engkau tidak akan mengkhianati aku dalam hal perjanjian yang telah kubuat untukmu. " Maka serigala itu mengangkat kaki depannya yang kanan dan meletakkannya dalam tangan Fransiskus. Sementara segalanya ini terjadi, semua orang dipenuhi rasa kagum dan gembira, haik karena rasa hormat terhadap orang kudus itu maupon karena sifat unik dari mukjizat itu dan perjanjian yang dibuat dengan serigala. Mereka semua mulai berseru ke surga, memuji dan memuliakan Allah yang telah mengutus Fransiskus kepada mereka dan berkat pahalapahalanya telah membebaskan mereka dari binatang kejam.

Setelah peristiwa ini serigala itu masih hidup dua tahun di Gubbio. Ja biasa masuk-keluar rumah sebagai sahabat tanpa menyakiti seorang pun. Penduduk kota memberinya makan dengan senang hati dan tidak seekor anjing pun yang menyakitinya sementara ia keliling kota. Sesudah dua tahun serigala itu mati karena usia tua. Seluruh penduduk kota bersedih hati karena setiap mereka melihatnya berjalan dengan lembut sekeliling kota, mereka mengenang keutamaan dan kekudusan Fransiskus. 
Serigala di Gubio, lambang permusuhan makhluk eiptaan dengan manusia, didekatinya tanpa senjata kekerasan tetapi dengan damai persandaraan.

(Fïoretti 2I)

Lebil lanjut kisah-kisah berikutnya ini mau menunjukkan bagaimana Fransiskus bergaul dengan alam semesta yang penuh pengliargaan dan demi pelestariannya. Persahabatannya dengan alam yang berlandaskan belaskasih, timbal balik dan menyelamatkan itu menimbulkan sukacita, lupa diri dan kekaguman yang luar biasa pada Allah Penciptanya.

Bila para saudara mencari kayu bakar, Fransiskus menginstruksikan agar mereka mengambil ranting-ranting saja dan sekurang-kurangnya meninggalkan tunggulnya supaya masih ada harapan bertunas baru. Tukang kebun dimintanya agar tidak menggarap semua lahan, tetapi membiarkan sebidang tanah kosong supaya masih ada tempat bagi bibit bunga dan rumput yang jatuh untuk tumbuh dan berkembang.

(2Celano 165)

Alangkah besar kegembiraan yang ditimbulkan dalam hatinya oleh keelokan meriab bumga-bunga, jika ia melihat kemolekamnya dan menghirup bau harumnya yāng sèdap itu. Segèra ia mengalihkañ pandangan matanya kepada keindahan bunga yang tumbuh berseri-seri di musim semi dari taruk Yesse itu dan yang menghidupkan kembali ribuan orang mati yang tak terbilang jumlahnya dengan keharumannya.

Jika ia menjumpai bunga yang besar jumlahnya, ia lalu berkotbah kepada mereka dan mengajak mereka untuk memuji Tulian, seakan-akan bunga itu makhluk yang berakal budi. Begitu pula ia mengingatkan ladang-ladang gandum dan keloun-kehun anggur, bukit-bukit batu dan hutan-hutan serta segala padang yang permai, sumber-sumber yang membual dan kebun-kebun subur yang menghijau, tanah dan api, udara dan angin, kepada cintakasih Allah, dan menganjurkan kepadanya untuk kepatuhan yang riang. 
Akhimya segala makhluk disebutnya saudara, dan dengan cara unggul yang tidak pernah dialami orang lain, ia menembus dengan ketajaman hatinya sampai ke dalam rahasia sekalian makhluk, karena ia sudah meningkat masuk ke dalam kemerdekaan kemuliaan anak-anak Allah. Kinj ia yang memuji engkau, ya Yesus yang mengagumkan, bersama dengan para malaikat; ia yang di dunia sudah mewartakan Engkau kepada segala makhluk sebagai yang patut dicintai.

(1Celano $X X X X, 81)$

Persahabatan dengan alam semesta ala Fransiskus entah dengan sesama makhluk ciptaan entah dengan lingkungan alam sekitar menunjukkan bahwa ia sungguh masuk ke inti atau kedalaman setiap ciptaan dan menemukan Allah di dalamnya dengan relasi cinta mistik. Memang ajaran tentang Allah yang tinggal dalam alam semesta dan semua ciptaan menyerap habis diri-Nya hingga bersifat ilahi itu sudah diajarkan oleh paham pantheisme ( pan $=$ semua, theos $=$ Allah, ilahi, isme $=$ paham). Namun pengalaman Fransiskus dari persahabatannya dengan alam bukan termasuk paham pantheisme tetapi panentheisme ( pan $=$ semua, $e_{n}=$ ada dalam inti/kedalaman, theos $=$ Allah, ilahi, isme $=$ paham), karena adanya Allah bukan diserap habis oleh semua ciptaan melainkan Allah tinggal dalam inti/kedalaman dari setiap ciptaan-Nya. menyatakan eksistensi dan kemuliaan-Nya lewat keberadaan setiap ciptaan itu sehingga setiap ciptaan-Nya dapat memanearkan/memantulkm sedikit dari kemuliaan Allah yang misteri, transendèn dan tak terkatakan sepenuhnyà. ${ }^{+}$

Fransiskus melihat bahwa ciptaan dapat memancarkan Penciptanya, sehingga ia melihat Allah Pencipta semesta alam dalam ciptaan-Nya dan ciptaan scbagai tangga untuk naik kepada Allah Pencipta: "Lewai pemandangan-pemandangan yang menvenangkan. hatinya bangkit kepada Dasar dan Sehab yang menghidupkan. Dalam hal-hal yang indah diliharnya Yang Mahaindah. Ia mengikuni Sang Kekasili lewat jejak-jejak yang ditinggalkan pada benda-benda dan dari

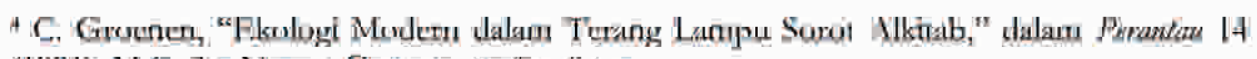

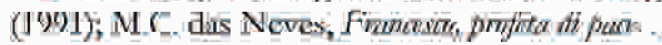


semuanya dibuat baginya tanggo jang dapat dinaikinya untuk sampai kepada Dia yang sepemuhnya amat menarik itu" (Legenda Maior IX. 1)."

Karena Allah Pencipta dilihat dalam ciptam-Nya dan ciptaam sebagai tangga untuk naik kepada Allah Pencipta, maka apa yang Fransiskus lihat dalam ciptaan selalu diarahkan kepada Allah Penciptanya. Ketika melihat anak domba yang lemah lembut dan dibawa ke tempat pembantaian, ia ingat Yesus, Anak Domba Allah yang disalibkan (Legenda Maior VII.6; ICalano XXVП1.77); ketika dilihatnya cacing yang meliuk-liuk kepanasan dan diinjak orang, ia melihat Kristus yang meliuk-liuk di salib (ICelano XXIX,80); ketika melihat keindahan bunga yang mekar berseri di musim semi dan harumnya membangkitkan orang mati, ia berpikir tentang Yesse, taruk dan tunas Daud, Yesus Kristus (ICelano XXIX,81); ketika dilihatnya ladang gandum, kebun anggur, bukit batu, hutan, padang permai, sumber air membual, kebun subur menghtjau, tanah, api, udara dan angin, ia merasakan betapa besamya kasih Allah (1Celano XXIX.81); ketika melihat batu, ia terarah pada Yesus, batu yang dibuang oleh tukang bangunan telah menjadi Batu Penjuru/Sendi (2Celano 165). ${ }^{6}$

Ciptaan yang memantulkan Penciptanya dan mengaralikan pikirannya pada Yesus Kristus itulah sebagian dari pandangan Kristologis dan Teologi Trinitas Fransiskus yang menempatkan Yesus, Putera Allah, sebagai sentral dalam karya penciptaan, penebusan dan penyelamatan, karena dengan perantaraan Putra-Nya dan dalam Roli Kudus, Allah telah menciptakan segala sesuatu yang rohani dan jasmani (AngTBul XXII, 1-3). Manusia pun diciptakan menurut citra Allah dan telah ditehus dengan peneurahan darah Kristus di salib: "Kasih sayang hatinya membuat ia menjadi suuctara bagi makhtuk-makhluk laim. sehingga ridak mengherankan kalau cima kasihnya membuan ia lehih bersaudara dengan mereka yang diciptakan menurut citra sumg Pencipta dan ditehtus oleh darah sang Penyelama " (Legenda Maior IX,4).

Persahabatan Fransiskus dengau sesama manusia, sesama makhjuk eiptaan dan lingkungan alam harus diletakkan dalam

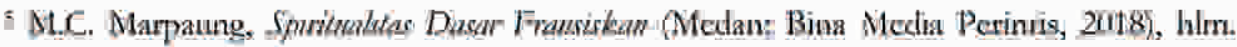
511.

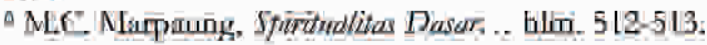


hubungannya dengan Allah Pencipta. La melihat dirinya, segala makhluk dan lingkungan alam sebagai sama-sama atau sesama ciptaan yang berasal dari satu asal yaitu Allah Penoipta semesta alam, sehingga semua makhluk ciptaan dipandang, diperlakukan dan dieintainya sebagai saudara dan saudari: "Dengan memandang asal segala makhluk, maka ia dipenuhi dengan takia yang berlimpah-limpah. Makhluk-makhluk

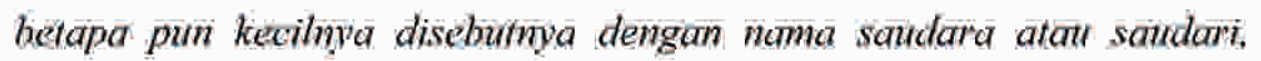
justru karena setahunya mereka sekalian mempunyai sanu asal seperti ia sendin" (Legenda Maior VIII,6).

Mengapa Fransiskus bersikap terhadap alam seperti itu? Fransiskus melihat alam semesta bukan terutama dari segi kegunaannya demi pemenuhan kebutuhan dan peningkatan mutu hidup, tetapi lebih pada nilai yang ada dalam diri alam semesta itu sendiri dan arti simbolis sakramentalnya. Keberadaan setiap makhluk bukan saja karena bermanfaat bagi manusia, tetapi juga karena memiliki nilai dalam dirinya sendiri dan menjadi lambang yang mewahyukan dan menghaditkan Allah. Oleh karena itu, manusia tidak boleh mengeksploitasinya sesuka hati. Setiap makliluk memiliki kesamaan, yakni sama-sama sebagai ciptaan Allah, sehingga semuanya sederajat dan Fransiskus menyapanya dengan sebutan kita semua adalah saudara-saudari. Semua itu terjadi dalam terang cahaya relasional yang sangat mendalam antara makhluk eiptaan dengan Yesus Kristus, sebagaimana nampak dalam keyakinan Fransiskus bahwa Kristuslah sumber kesatuan dan pendamai antar ciptaan: "Aku minta kepada kalian semuā. saudara-saudaraku. dengan mencium kakimu dan dengan kasih yang sebesar-besarma, agar kamusesuai dengan kemampuanmu - menyatakan segala hormat dan hikmat kepada tubuh dan darah maha kudus Tuhan kita Yesus Kristus Di dalam. Dia. segala sesuatu yang ada di surga di di bumi diperdamaikan dan dipersankan kembali dengan Allah yang maluakuasa" (SurOr 12-13)."

Bagaimana dapat bersikap terhadap alam seperti Fransiskus? Kita harus bersikap seperti [ransiskus yang menjadi manusia kontemplatif daripada rasionalis. Maka kita harus melepaskan mentalitas rasionalis yang menganggap pendekatan rasionalis terhadap alamlah satu-satunya

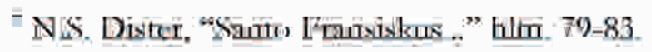


yang repar dan memupuk mentalitas kontemplatif yang memandang sampai dasar/inti terdalam dari alam dan makhluk ciptaan lannya. yakni hakekatnya sebagai bayangan dan gambaran yang menampakkan Allah di dunia ini. ${ }^{8}$

Ungkapan sikap persahabatan Fransiskus yang sangat mendalam dengan alam semesta tertuang dalam Gita Sang Surya (Kidung Saudara Matahari), yaitu madah pujian kepada Allah Pencipta dengan perantaram dan berșuma dengana âlam dan segala makhluk eiptaan. Gita Sang Surya, yang digubah dua bulan menjelang kematiannya, menyingkapkan kedekatan Fransiskus dengan alam dan segala makhluk ciptaan. Di dalamnya terpatri jiwa persahahatan akrab: Ftansiskus dengan alam dan semua makhluk ciptaan yang diperlakukannya sebagai saudara-saudari dan yang dipersatukannya dalam komunitas besar semesta alam. Di sana setiap ciptaan dengan kekhasan yang dimilikinya masing-masing mempunyait tempat dan peranannya, yaitu yang ditatap (bintang-bintang, matahari, bulan, benda-benda di langil. dll.), yang dikagumi (keindahan, kedalsyatan, dll.) dan yang sejauh perlu digunakan dalam memelihara kehidupan manusia (tumbuh-tumbuhan, hewan. dII.) ${ }^{9}$

\section{Gita Sang Surya}

\section{(Kidung Saudara Matahari) ${ }^{10}$}

1. Yang Mahaluhur. Mahakuasa, Tuhan yang baik, milik-Mulah pujaan, kemuliaan dan hormal Bdk. dan segala puj̣ian.

2. Kepada-Mu saja, Yang Mahaluhur, semuanya itu patut disampaikan. namun tiada insan satu pun layak menyehut nama-Mu.

3. Terpujilah Engkau, Tuhaku, Bdk. Bersama semua makhluk-Mu, terutama Tuan Saudara Tob: 8:7 Măahari: dia terang siang hari, melahii dia kami Kau beri terang.

4. Dia indah dan bercahaya dẹngar sinar cahaya yang

\footnotetext{
8 N.S, Disrer, "Santo Fransiskıs..." hlm, 79

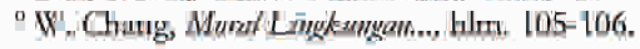

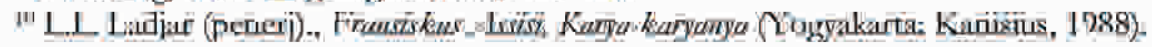


cemerlang; tentang Engkau, Yang Mahaluhur,

dia menjadi tanda lambang.

5. Terpujilah Engkau, Tuhanku, karena Saudari

Bulan dan Bintang-bintang, di cakrawala Bdk

Kau pasang mereka, gemerlapan, megah dan indah. Mzm 1.48:3

6. Terpujilah Engkau, Tuhanku, Karena Saudara

Angin, dan karena udara dan kabut. Karena langit Bdk.

yang cerah dan segala cuaea,

Dan 3:64-65

Dengannya Engkau menopang hidup makhluk

Mzm 104:13-14 ciptaan-Mu.

7. Terpujilah Engkau, Tuhanku,Karena Saudari Air; Bdk.

Dia besar faedahnya, selalu merendah, berharga dan Mzm 148:4-5 murni.

8. Terpujilah Engkau, Tuhanku,

Bdk.

Karena Saudari Api, dengannya Engkau menerangi Dan 3:66

malam;

Dia indah dan cerah ceria, kuat dan perkasa.

$\operatorname{Mzm} 78: 14$

9. Terpujilah Engkau, Tuhanku,

Karena Saudari kami lbu Pertiwi; $\quad$ Bdk.

Dia menyuap dan mengasul kami,

Dan 3:74

dia menumbuhkan aneka ragam buah-bualian,

beserta bunga warna-warnf dan rumput-rumputan. Mzm 104:13-14

10. Terpujitah Engkau. Tuhanku.

Karena mereka yang mengampuni demi kasih-Mu, Bdk.

Dan yang menanggung sakit dan duka derita.

Mat 6:12

11. Berbahagialah mereka, yang menanggungnya

Bdk.

dengan tenteram. Karena oleh-Mu. Yang Mahaluhur. Mat 5:10

mereka akan dimahkotai.

12. Terpujulah Engkau, Tuhanku.

Karena Saudari kami Maut badani,

Daripadanya tidak akan terluput insan hidup satu pun.

13. Celakalah mereka yang mati dengan dosa herat;

Berbahagialah mereka yang didapatinya setia pada

Bdk.

kehendak-Mu tersuci, Karena mereka takkam

Why $2: 11: 20: 6$

ditimpa maut kēdua.

14. Pujalah dan pujilah Tuhanku, 
$\begin{array}{ll}\text { Bersyukurlah dan mengabdilah kepada-Nya } & \text { Bdk: } \\ \text { Dengan merendahkan diri serendah-rendahnya. } & \text { Dan 3:85 }\end{array}$

Tulisan tertua tentang Gita Sang Surya tertemukan dalam Codex 338 yang ditulis thn. 1250 dan kini masih tersimpan di Perpustakaan dari Basilikā St. Fransiskus di kota Asisi. Sedangkan motif penulisannya, Gita Sang Surya erat kaitannya dengan peristiwa stigmatisasi Fransiskus di La Verna. Stigmatisasi itu merupakan puncak pengalaman pertemuan dan persatuan Fransiskus dengan Allah. Meterai kehadiran kasib Allah dalam rupa luka-luka suci pada tubuhnya itulah yang menghantar Fransiskus pada kesadaran akan kebesaran Allah yang nyata dalam setiap ciptaanNya. Oleh karena itu, ia menggubah Gita Sang Surya secara bertahap. Ay. 1-9 digubah sewaktu Fransiskus sakit keras dan dirawat di biara Klaris San Damiano pada musim dingin tahun 1224/1225. Ay.10-1I, yang berbicara tentang pengampunan dan damai, merupakan hasil gubahamnya di kediaman uskup Asisi Guido 11 untuk meredakan konflik antara sang uskup dan walikota Asisi Aportolo Bernadi pada musim panas tahun 1225. Ay.12-13, yang berbicara tentang maut, ditulis di Portiuncula setelah ia menerima wahyu bahwa kematiannya sudah mendekat. Sedangkan ay. 14 menjadi penutup, yang merupakan ajakan untuk ambil bagian dalam memụi Allah bersama semua ciptaan. ${ }^{1 t}$

Dengan Gita Sang Surya Fransiskus memaparkan bahwa dari kodratnya alam dan setiap makliluk ciptaan ambil bagian dalam kemuliaan dan kesempurnaan Allah Penciptanya. Baginya, alam dan semua makhluk ciptaan berpetan sebagai pengantara karya peneiptaan Allah. Ciptaan merupakan medium, sarana yang melaluinya Allah menyatakan kasihNya kepada ciptaan lainnya. Lewat matahári, Allah menerangi kita dan makhluk ciptaan lainnya (ay.3); lewat angin, udara dan cuaca, Allah menopang kehidupan sekalian makhluk (ay.6); dan lewat api, Allah menerangl malam (ay.8). Dengan demikian karena ciptaan dapal menjadi medium dari pihak Allah, maka oiptaan itu pun dapat menjadi medium lewat mana manusia sampai kepada Allah.

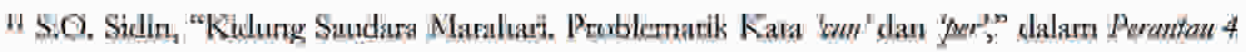
(J991), hlm. J03-J0H. 
Meskipun secara fisik mata Fransiskus sakit dan tidak tahan melihat cahaya, namun berkat pengalaman masa lalu dan meditasinya yang mendalam, ia dapat menembus kedalaman alam semesta dan menemukan Allah di balik alam dan segala makhluk ciptaan-Nya. ${ }^{12}$

Dengan Gita Sang Surya Fransiskus mau mengungkapkan unsurunsur penting, yaitu pengangkatan martahat makhluk eiptaan Tuhan dengan sapaan klias dan perlakuan sebagai saudara-saudari: penghargaan kekhasan nilai-nilai instrinsik dalam diri setiap makhluk yang hanya bergantung pada Tulan Pencipta semesta alam: penyadaran diri manusia sebagai salah satu bagian dari alam semesta dan perangkulan makhlukmakhluk ciptaan lainnya sebagai rekan dalam memuliakan Tuharı. Untuk itu Franisiskus terus berjuang membentuk suatu persahabatan universal yang mencakup semua ciptaan tanpa tembok-tembok pemisah. ${ }^{13}$

Demikianlah Fransiskus memandang dan memperlakukān alam dan setiap makhluk ciptaan sebagai sesama ciptaan Allah yang disebutnya saudara dan saudari. Allasil, pandangan dan perilaku Fransiskus itu berdampak langsung pada relasinya baik dengan alam, segala makhluk ciptaan maupun dengan Tuhan. Bagi Fransiskus alam semesta merupakan tempat kehadiran Tuhan. Melalui alam Tuhan memperkenalkan dri-Nya dan alam menyajikan simbol-simbol yang berbicara tentang Tuhan Misal, dalam Gita Sang Surya Fransiskus memyapa saudara matahari sebagai "pembawa lambang-Mu, Sang Mahaluhur." Penghayatan ini membuat Fransiskus memandang alam sebagai sumber yang mendorongnya untuk bermadah puji dan bersyukur kepada Tuhan Penciptanya. Bahkan dalam Gita Sang Surya ia mengungkapkan lebih dalam lagi, yaitu di saat ia merasa tidak layak dan tidak sanggup memuji Tuhan, unsur-unsur alam itu mengambil alili dan meneruskan lagu pujiannya. ${ }^{\text {It }}$

Fransiskus pun memandang makhluk eiptaan sebagai saudarasaudari dan bersahahat dengan eiptaan yang ganas, saudari api, yang:

\footnotetext{
12 S.O. Sidu, "Kidung Saudara.:" him. 108-110.

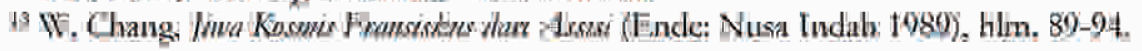

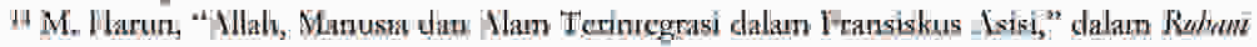

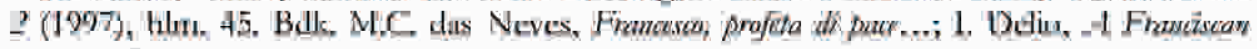
Viññf Gnatiog.
} 
dipakai dokter sewaktu penyembuthan matanya: Ketika sang tabib mau menempelkan besi merah menyala pada pelipisnya ia mengatakan: "Saudariku api, keindahanmu melebihi apa saja di dumia ini Sang Mahatinggi menciptakkm engkau kuat serta indah dan berfaedah. Berlakulah ramah terhadapka pada saat ini. Kepada yang Mahaagung vang telah menciptakan engkan aku mohon agar ia mengurangi panasmu sekarang, sehingga aku bisa tahan bila engkau membakar aku dengan lembut. Selelah selasai berdua. ia menandai api dengan tanda salib" (2Celano J66, Legenda Perugia 86).

Hormatnya kepada saudari api pun nampak dalam kisah berikut: "Pada waktu matahari terbit, sepantasnalah semua orang memuii Allah karena ia telah menjadikan benda langit ini vang memberikan terang kepacla mata kita sepanjang hari, dan pada waktu petang, bila senja tiba sepatutnvalah semua orang memuji Allah karena ciptaan yang lain itu. saudari kita api, yang menungkinkan mata kita melihat pada malam vang gelap. Kita semua seperti orang buta. tetapi melahi kedua makhluk ciptaan ini Allah menberikan kita terang " (Legenda Perugia 83).

Penghayatan bahwa alam dan segala makhluk di dalamnya adalah ciptaan Allah, pun kesadaran bahwa dirinya sendiri merupakan bagian dari makhluk ciptaan itulah yang menumbuhkan dalam diri Fransiskus sikap penghargaan dan perlakuan terhadap alam dan setiap makhluk ciptaan sebagai saudara-saudarinya yang bersama-sama membentuk satu keluarga Allah. Semua dipanggilnya sébagai saudara-saudari dan diperdamaikan satu sama lain secara berpasang-pasangan. Bulan dan bintang-bintang dipasangkan dengan matahari, air dijodohkan dengan angin, bumi dijadikan partner api, dan maut didamaikan dengan cintakasih, sehingga semuanya merupakan satu persatuan dan persaudaraan universal di hadapan Allah. ${ }^{15}$

Pengakuan bahwa semua ciptaan adalah saudara dan saudari itu pun merupakan wujud kerendahan hati Fransiskus, sebah dengan pengakuan itu ia menyatakan dininya tidak lebih darí makliluk eiptaan lainnya, betapa pun makhluk ito begitu kecil. Fransiskus tidak menempatkan diri di atas makhluk ciptaan lainnya dan tidak

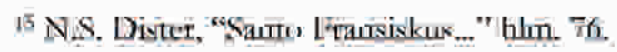


menguasainya, sebab di hadapan Allah ia sadar akan dirinya sebagai ciptaan-Nya dan di hadapan makhluk ciptaan lainnya ia sadar akan dirinya sebagai sesama makhluk iptaan. Gita Sang Surya menguak kerendahan hati dan persaudaraan universal Fransiskus. ${ }^{16}$

Kerendahan hati, penghargaan dan perlakuan bahwa semua makhluk dan alam eiptaan adalah sesama dan saudara-saudari itulah yang membuat Fransiskus bersaliabat dengan alam semesta dan sẹgala isinya. Spiritualitas seperi inilah yang membuatnya hormat terhadap alam dan semua makhluk ciptaan serta tidak memperlakukān àtāu memanfaaikannya demi kebutuhan dan keuntungan pribadi. Mengapa Fransiskus bersikap terhadap alam semesta seperti itu?

Fransiskus melihat alam bukan terutama dari segi kegunaannya demi pemenuhan kebutuhan dan peningkatan mutu hidup, tetapi lebih pada nilai yang ada dalam diri alam itu sendiri dan arti simbolis sakramentalnya. Ia pun memandang keberadaan setiap makhluk ciptaan bukan saja karena bermanfaat bagi manusia, tetapi karena memiliki nilai dalam dirinya sendiri dan menjadi lambang yang mewahyukan dan menghadirkan Allah. Oleh karena itu. Fransiskus berkeyakinan bahwa manusia tidak boleh mengeksploitasi alam dan menguasai sesama makhluk ciptaannya sesuka hati. Lingkungan alam dan setiap makhluk ciptaan, termasuk manusia, memiliki kesamaan, yaitu sama-sama sebagai ciptaan Allah, sehingga semuanya sederajat dan Fransiskus menyapanya dengan "kita semua adalah saudara-saudari." Semua itu terjadi dalam terañ cahayà relasional yang sangat mendalam antăra makhluk ciptaan dengan Yesus Kristus, sebagaimana nampak dalam keyakinan Fransiskus bahwa Kristuslah sumber kesatuan dan pendamai antar eiptaan.

Aku mohon kepada kamu semua, Saudara-saudaraku, dengan mencium kakimu dan dengan kasih yang sebesar-besarnya, agar kamu, sesuai dengan kemampuanmu, menyatakan segala hormat dan khidmat kepada Tubuh dan Darah Mahakudus Tuhan kita Yesus Kristus; di dalam Dia, segala sesuatu yang ada di surga di di bumi diperdamaikan dan dipersarukan kembali dengan Allah Yang Mahakuasa.

(Surat kepadu Seluruh Ordo l2-13)

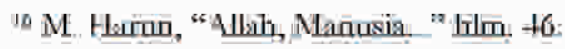


Dalam berbagai tulisannya Fransiskus pun menegaskan bahwa manusia harus meneari kemuliaan Allah dalam makhluk eiptaan-Nya (DrBap 5), karena Allah itu satu-satunya sumber segala kemuliaan (AngTBul 23:9), bahkan bukan saja sumber segala kebaikan tetapi Kebaikan itu sendiri (PujAllah 3-4; 2SurBerim 62; UrBap 2; Pujth 1]; AngTBul 23.9) dan satu-satunya yang mengerjakan yang baik (Pth 2:3: $7: 4 ; 11: 12 ; 20: 12-13.28)$, yang kepada-Nya kita harus mengembalikan semuanya yang baik dan mengakui bahwa semua yang baik adalah milikNya (AngTBul 17:17)..$^{17}$

Dengan demikian Gita Sang Surya merupakan ungkapan iman Fransiskus akan kehadiran Allah dalam dan lewat eiptaan-Nya. Baginya, semua ciptaan menghadirkan dan menampakkan Allah menuruk cara dan kadar keberadaannya masing-masing. Baginya, alam semesta merupakan medium yang membimbing langkahnya menuju persatuan cinta mesra dengan Allah, Oleh karena itu, Gita Sang Surya merupakan madah pujian kepada Allah Pencipta dan karya-Nya serta ciptaan-Nya, yailu semua benda tak bernyawa (matahari, bulan dan bintang) dan keempat unsur kosmis (udara, air, api dan tanah dengan cirinya masing-masing). ${ }^{18}$

Gita Sang Surya juga merupakan madah syukur kepada Allah Peneipta karena berkat-Nya yang diperuntukkan bagi manusia, yaitu berkat ilahi bagi yang berbuat baik (orang yang membawa damai, orang yang menderita dan menanggung derita fisik maupun psikis karena cinta akan Allah, dan orang yang mengalami kematian badani tetapi tak akan ditimpa maut kedua). Gita Sang Surya pun merupakan undangan kepada seluruli umat manusia untuk memuji, bersyukur dan mengabdi Allah dengan rendah hati. Puji syukur umat manusia ini merangkum pujian dan syukur seluruh alam semesta atau segala ciptaan Allah. Logikanya. Fransiskus sudah berada di puncak pertobatannya dan sepenuhnya terarah kepada Allaih sehingga indera batinialnya semakin tajam dan memampukannya untuk menangkap segala puja-puji semua makhluk ciptaan. Pada saat yang sama ia menyadari bahwa dirinya juga ciptaan,

1- UrBap = Tiraian Dos Bapa Kamis AngTBul = Anggaran Dasar Tanpa Bulla, Puy Nllah = Pupian bagi Allah Yang Mahaluhur; 2SurBerim = Surat Kedua kepada Kaurn Berimary

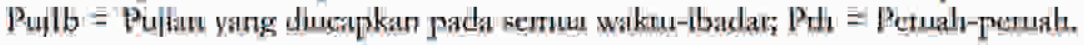

${ }^{18}$ SO. Sidin, "Kidnog Ssmdacr..." blim. 111-112. 
sehingga semua makhluk ciptaan disebutnya sesama/saudara-saudari dan diajaknya untuk bersama-sama memuji Sang Pencipta alam semesta.

Gita Sang Surya memiliki padanan dalam Kitab Suci yang menginspirasi atau mengandung kemiripan ide dengannya. Berikut padanannya tersebut.

\section{Langit dan Bumi, Pujilah TuHAN}

\section{(Mzm 148:1-14)}

'Haleluya! Pujilah TUHAN di surga, pujilah Dia di tempat tinggi!

${ }^{2}$ Pujilah Dia, hai segala malaikat-Nya, pujilah Dia, hai segala tentara-Nya! ${ }^{3}$ Pujilah Dia, hai matahari dan bulan, pujilah Dia. hai segala bintang terang! ${ }^{4}$ Puyilah Dia, hai langit yang mengatasj segala langit, hai air yang di atas. langit!

Baiklah semuanya memuji nama TUHAN, sebab Dia memberi perintah, maka semuanya tercipta. ${ }^{6} \mathrm{Dia}$ mendirikan semuanya untuk seterusnya dan selamanya, dan memberi ketetapan yáng tidak dapat dilanggar.

${ }^{7}$ Pujilah TUHAN di bumi. hai ular-ular naga dan segenap samudera raya; "bai api dan hujan es, salju dan kabut, angin hadai yang melakukan fïrmañ-Nya: "hai gumung-gurung dan segala bukit, pohon buah-buahan dan segala pohon aras; "hai binatang-binatang liar dan segala hewan, binatang melata dan burung-burung yang bersayap; "hai raja-raja di bumi dan segala tangsa, pembesar-pembesar dan semua pemerintah dunia; ${ }^{12}$ hai teruna dan anak-anak dara, orang tua dan orang. muda!

${ }^{13}$ Biarlah semua memuji-muji TLIHAN, sebab hanya nama-Nya saja yang tinggi luhur, keagungan-Nya mengatasi bumi dan langit, ${ }^{\text {ra }}$ la telah meninggikan tanduk umat-Nya, menjadi puji-pujian bagi semua orang yang dikasihi-Nya, bagi orang Israel, umat yang dekat pada-Nya. Haleluya! 


\section{Lagu Pujian Ketiga Pemmda dalam Tanur Api}

\section{(T.Dan 3:51-90)}

St Maka ketiga orang di dalam perapian ítu semulut melambungkan suatu lagu untuk memuliakan dan memuji Allah. katanya:

52 Terpujilah Engkau, Tuhan, Allah nenek moyang kami, yang patut dihormati dan ditinggikan selama-lamanya, terpujilah nama-Mu yang muliạ dan kudus, yang patut dihormati dan ditinggikan selama-lamanya.

${ }^{53}$ Terpujilah Engkau dalam Bait-Mu yang mulia dan kudus, Engkau patut dinyanyikan dan dimuliakan selama-lamanya.

54. Terpujilah Engkau di atas takhta kerajaan-Mu, Engkau patut dinyanyikan dan dimuliakan selama-lamanya.

5. Terpujilah Engkan yang mendugai samudera raya dan bersemayam di atas kerub-kerub. Engkau patut dihormati dān ditinggikan selamalamanya.

56. Terpujilah Engkau di bantangan langit, Engkau patut dinyanyikan dan dimuliakan selama-lamanya.

${ }^{57}$ Pujilah Tuhan, hai segala buatan Tuhan, nyanyikanlah dan tinggikanlah Dia selama-lamanya.

58 Pujilah Tuhan, hai segala malaikat Tuhan, nyanyikanlah dan tinggikanlah Dia selama-lamanya.

${ }^{50}$ Pujilah Tuhan, hai segenap langit, nyanyikanlah dan tinggikanlah Dia selama-lamanya.

of Pujilali Tuhan, hai segala air di atas langit, nyanyikanlah dan tinggikanlah Dia selama-lamanya.

${ }^{6 t}$ Pụijlah Tuhan, hai segala tentara Tutan, nyanyikanlah dan tinggikanlah Dia selama-lamanya.

${ }^{62}$ Pujilah Tuhan, hai matahari dan bulan, nyanyikanlah dan tinggikanlah Dia selama-lamanya.

03. Pujilah Tuhan, hai segala bintang di langit. nyanyikanlah dan tinggikanlah Dia selama-lamanya. 
64 Pujilah Tuhan, hai segala hujan dan embun, nyanyikanlah dan tinggikanlah Dia selama-lamanya.

${ }^{65}$ Pujilah Tuhan, hai segala angin, nyanyikanlali dan tinggikanlah Dia selama-lamanya.

${ }^{66}$ Pujilah Tuhan, hai api dan panas terik, nyanyikaniah dan tinggikanlah. Dia selama-lamanya.

${ }^{67}$ Pujilah Tuhan, hai kedinginan dan pembekuan, nyanyikanlah dan tinggikanlah Dia selama-lamanya.

${ }^{68}$ Pujilah Tuhan, hai embun dan salju yang membadai, nyanyikanlah dan tinggikanlah Dia selama-lamanya.

${ }^{60 \%}$ Pujilah Tuhan, hai es dan kedinginan, nyanyikanlah dan tinggikanlah Dia selama-lamanya.

7 (t Pujilah Tuban, hai embun beku dan salju, nyanyikanlah dan tinggikanlah Dia selama-lamanya.

7t Pụilah Tuhan, hai siang dan malam, nyanyikanlali dan tinggikanlah Dia selama-lamanya.

72 Pujilah Tulian, hai cahaya dan kegelapan, nyanyikanlah dan tinggikanlah Dia selama-lamanya.

${ }^{73}$ Pujilah Tuhan, hai halilintar dan awān-kèmawan, nyanyikanlah dān tinggikanlah Dia selama-lamanya.

74 Biarlah bumi memuji Tuhan, nyanyikanlah dan finggikanlah Dia selama-lamanya.

${ }^{75}$ Pujilah Tuhan, hai gunung-gemunung, nyanyikanlah dan tinggikanlah Dia selama-lamanyà.

${ }^{76}$ Pujilah Tuhan, hai segala tumbuhan di bumi, nyanyikanlah dan tinggikanlah Dia selama-lamanya.

77 Pujilah Tuhan, hai segenap mata air dan bukit, nyanyikanlah dan tinggikanlah Dia selama-lamanya.

${ }^{7 \times}$ Pujilah Tuhan, hai lautan dan sungai, nyanyikanlah dan tinggikanlah Dia selama-lamanya. 
${ }^{7 \%}$ Pujilah Tuhan, hai raksasa lautan dan segala apa yang bergerak di dalam air, nyanyikanlah dan tinggikanlah Dia selama-lamanya.

suif Puilab Tuhan, hai unggas di udara, nyanyikanlah dan tinggikanlah Dia selama-lamanya.

st Pụjilah Tukan, hai segala binatang buas dan ternak di bumi, nyanyikanlah dan tinggikanlah Dia selama-lamanya.

${ }^{82}$ Pujilah Tuhan, hai anak-anak manusia, nyanyikanlah dan tinggikanlali Dia selama-lamanya.

${ }^{83}$ Pujilah Tuhan, hai lsrael, nyanyikanlah dan tínggikanlah Día selamalamanya.

${ }^{84}$ Pujilah Tulhan, hai para imam Tuhan, nyanyikanlah dan tinggikanlah Dia selama-lamanya.

${ }^{85}$ Pujilah Tuhañ, hai para hambā Tuhàn. nyanyikanlah dañ tinggikanlah Dia selama-lamanya.

${ }^{86}$ Pujilah Tuhan, hai roh dan jiwa orang-orang benar, nyanyikanlah dan tinggikanlah Dia selama-lamanya.

${ }^{87}$ Pujilah Tuhan, hai semua yang mursid dan rendah hati, nyanyikanlah dan tinggikanlah Dia selama-lamanya.

${ }^{88}$ Pujilah Tuhan, hai Hananya, Azarya dan Misael, nyanyikanlah dan tinggikanlah Dia selama-lamanya. Sebab dari dunia orang mati kita telah dilepaskan-Nya, dari genggaman maut diselamatkan-Nya dan kita direnggut-Nya dari nyala api perapian yang menyala, dari tengah-tengah api kita telah direnggut-Nya.

89. Bersyukurlah kepada Tuhan. sebab la baik. bahwasannya untuk selama-lamanya kasih setia-Nya.

${ }^{90}$ Pujilah Allah di atas segala allah. hai kamu semua yang takut kepada Tuhan, bernyanyilah dan bersyukurlah, bahwasannya untuk selamalamanya kasih setia-Nya. 


\section{Pujian bagi Tuhan Semesta Alam}

\section{(Sir 42: 15-43:33)}

Sir 42: 15-43:33 merupakan madah yang meluhurkan karya Sang Pencipta dengan segala kemuliaan dan kebijaksanaan dalam alam. Unsur pujian kadang hilang karena gambaran yang begitu mendetail tuntang alam. tetapi dengan Sir 42:15-25 dan Sir 43:27-33 segala sesuatumya dijadikan alasan bagi manusia untuk memuji kelulturan dan kebijaksanaan Allah. Dalam Sir 42:15-43:33 Putra Sirakh merenungkan kuat kuasa, keindahan dan kebaikan Allah sebagaimana dinyatakan dalam kebesaran karya penciptaan dan pelestarian alam semesta $(42: 15-17,22-25 ;$ 43:1-26), kemahatahuannya $(42: 18-20)$, kesempurnaan kebijaksanaan dan keabadiannya (42:21). Kesimpulannya adalah madah pujian yang meriah dan penuh semangat $(\underline{43: 27}-\underline{33})$.

42:15 Pekerjaan Tuhan hendak kukenangkan, dan apa yang telah kulihat hendak kukisahkan. Segala pekerjaan Tuhan dijadikan dengan firmanNya. ${ }^{10}$ Matahari bercahaya memandang segala sesuatunya dan ciptaan Tuhan itu penuh dengan kemuliaan-Nya. ${ }^{17}$ Kepada orang-orang-Nya yang kucus Tuhan tidak memberikan kemampuan untuk menceritakan segala buatan-Nya yang mengagumkan, yang telah ditentukan Tuhan alam semesta. supaya jagat raya didukung dengan kemuliaan-Nya.

${ }^{18}$ Lubuk lautan dan hati diselami oleh-Nya, dan segala rencananya diketahui-Nya. Sebab Yang Mahatinggi mengenal segala sesuatu yang dapat dikenal dan menilik tanda-tanda zaman. "19 Yang sudah-sudah diberitahukan-Nya dan juga apa yang datang, dan bekas dari apa yang tersembunyi pun disingkapkan-Nya. ${ }^{20}$ Tidak ada pikiran satu pun yang terluput dari pada Tuhan dan perkataan mana pun tak tersembunyi bagiNya.

${ }^{21}$ Ciptaan besar dari kebijaksanaan-Nya rapih diatur oleh-Nya, oleh karena dari kekal sampai kekal la ada. Tidak ada sesuatu pun yang dapat ditambahkan atau diambil dari padanya dan la tidak membutuhkan seorang pun sebagai penásehat. 
${ }^{22}$ Betapa eloklah segala eiptaan Tuhan, tetapi hanya sebagai bunga api sajalah apa yang nampak. ${ }^{2}$ Semuanya hidup dan tetap tinggal untuk selama-lamanya guma setiap keperluan, dan semuanya patuh kepada-Nya. ${ }^{24}$ Segala-galanya berpasang, yang satu berhadapan dengan yang lain, dan tidak ada suaru pum yang diciptakan-Nya kurang lengkap. ${ }^{5}$ Yang satu meinguatkan kebaikan dari yang lain. dan siapa gerangan pernali kenyang-kenyang memandang kemuliaan Tuhan?

43:1 Kebanggaan langit yāng tinggi ialah cakrāwala terang-benderang. dan langit kelihatan sebagai tontonan yang mulia. Pada terbitnya dan pada masuknya matahari mewartakan dirinya, sebagai alat ajaib buatan dari Yang Mahatinggi. ${ }^{3}$ Apabila rembang ia menghanguskan tanah, dam siapa gerangan dapal bertahan terhadap panas teriknya?

${ }^{A}$ Orang mengopak dapur supaya menjadi panas, tetapi matahari membakar gunung-gemunung tiga kali lipat; ia mengembuskan uap yang berapi, dan menyilaukan mata dengan sinar yang dipancarkannya. ${ }^{5}$ Agunglah Tuhan yang meneiptakannya dan dengan firman-Nya mempercepat peredarannya.

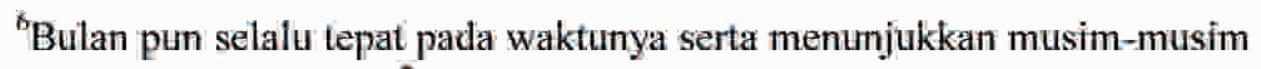
sebagai tanda abadi. 'Dari bulanlah datang tanda untuk mengadakan perayaan-perayaan, sebuah penerang yang bersusut setelah menjadi purnama. "Dari padanyalah bulan mendapat namanya, dan ia bertambali secara ajaih dalam peredarannya. Ia merupakan sebuah alamat bagi bala tentara di angkasa, dan bersinar di cakrawala.

"Keindahan langit ialah semarak bintang-bintangnya, perhiasan gilanggemilang di tempat tinggi Tuhan. "Sesuai dengan aturamya semua herdiri tetap karena firman dari Yang Mahakudus, dan tak jemu-iemu dalam penjagaannya. "Pandangilah pelangi dan pujilah Penciptamya, sebab teramat eloklah ia dalam semaraknya. ${ }^{12}$ Dengan serinya ia melingkungi bentangan langit, dan direntangkan oleh tangan dari Yang Mahatinggi.

${ }^{13}$ Tuhan menurunkan salju dengan firman-Nya, dan anak panah penghukuman-Nya dikilatkan-Nya. ${ }^{1 /}$ Karenanya gudang-gudang terbuka, dan awan-awan bagaikan burung terbang. ${ }^{15}$ Dengan kebesaran-Nya la menebalkan awan-awan, dan terpecahlah batu-batu es. 
${ }^{17}$ Demi suara gemuruh petir-Nya bumi masuk sakit beranak, "thin dan dengan melihatnya gunung-gemunung bergoncang.

${ }^{766}$ Angin dari sebelah selatan bertiup atas kehendak Tuhan, ${ }^{176}$ dan demikian pun taufan dari sebelah utara dan angin puting beliung.

${ }^{18}$ Salju dihamburkan-Nya bagaikan burung yang hinggap. dan turunnya laksana belalang yang mendarat. Keindahan putih metahnya dikagumj mata, dan hati terlicran karenā turunnya.

${ }^{\mathrm{t}}$ Bagaikan garam embun beku ditaburkan Tuhan, yang menjadi mata duri karena kedinginan.

${ }^{2}$ Bertiuplah angin utara yang dingin, dan di atas air terbentuklah es, Duduklah ia di atas setiap kumpulan air yang dilapisi seolah-olah dengan baju zurah. ${ }^{21}$ Angin utara menalang gunung-gemunung dan menghanguskan padang gurun, dan perumputan dimakannya seperti nyala api. "2 Semuanya cepat disembuhkan oleh kabut, dan sesudah panas terik semua disegarkan embun.

${ }^{23}$ Samudera raya diteduhkan oleh Tuhan dengan pikiran-Nya, dan di dalamnya pulau-pulau ditanam oleh-Nya. ${ }^{24}$ Yang mengarungi laut menceritakan tentang bahaya-bahayanya, dan mendengarnya dengan telinga kita keheran-heranan. ${ }^{25}$ Sebab hal-hal yang aneh dan menakjubkan terdapat di sana, yakni macam-macam binatang dan makhluk yang dahsyat. ${ }^{26}$ Oleh Tuhan maka pesuruh-Nya berhasil, dan karena firman-Nya semuanya rapil teratur.

${ }^{27}$ Masil banyak dapat kami katakan, tapi tidak akan sampai berakhir dan ringkasan segala perkataan ialah: "Dialah segala-galanya." ${ }^{28}$ Bagaimana gerangan kami mampu memuliakan Dia, sebab Dia adalah Yang Besar melampaui segala buatan-Nya. ${ }^{20}$ Tuhan mendahsyaikan dan teramal bessar, dan ajaiblă kekuasāañ-Nya.

3il Manakala kamu memuliakan Tuhan luhurkanlah Dia sedapat-dapatnya, meskipun la tetap melebihinya. Apabila kamu memasyhurkan Dia hendaklah dengan segenap tenagamu, dan jangan jemu-jemu, sebab tidak dapat kamu cukupkan.

${ }^{3}$ Siapakali yang melihat Dia sehingga dapat menceritakan-Nya, dan siapakah dapat membesarkan sebagaimana la adanya? 
${ }^{\text {I2 }}$ Banyak hal lebih hebal dari pada yang tadi masih tersembunyi, sebab cuma sedikitlah dari pekerjaan-Nya yang telah kami lihat. ${ }^{33}$ Sebab segala-galanya diciptakan oleh Tuhan; dan orang yang bertakwa diamugerahi-Nya dengan kebijaksanaan.

\section{Kesimpulan}

Dengan Cita Sang Surya Fransiskus menjadi seperti ketiga pemuda dalam tanur api (T.Dan 3:51-90) yang mengajak alam dan semua makhluk ciptaan memuji dan memuliakan Allah Pencipta semesta alam (ICélano XXIX,80). Dengan Gita Sang Surya ia bertindak seperti Daud karena madah itu terinspirasi dan sangat dekat dengan Mzm 148:1-14. Dengan Gita Sang Surya ia bermadah seperti Sir 42:15-17,22-25; 43:1-26 yang merupakan madah bagi Allah Peneipta alam semesta unuk mengagungkan kekuasaan, kemuliaan, kebijaksanaan dan kebaikan-Nya sebagaimana dinyatakan dalam kebesaran karya penciptaan dan pemeliharaan alam semesta. Kesimpulannya dengan madah Gita Sang Surya Fransiskus telah menunjukkan pemahamannya akan ini segala makhluk ciptaan dan kesadaran dirinya sebagai satu atau bagian dari eiptaan itu yang mendorongnya untuk mengasihi, merangkul, memelihara dan melestarikan baik alam maupun sesama makhluk ciptaan dalam kesatuan damai sejahtera yang menyelamatkan. McDonagh mengatakan: Dalam dunia zaman ini orang mengenang Fransiskus sxbagai penyembuh, pendamai dan tokoh kreatif Kenangan ini mengithami banyak orang menjadi toleran, giat membangun persaudaraan sejati di antara sesama manusia dan menolak perang sebehum terlambal hagi kemanusiaan dan bumi. Juga mengilhami para naturalist dan ekologist untuk menjaga alam jangan sampai dieksploitasi manusia. Perlindungan turhadap wilayali hutan belantara di dunia kita zaman ini mutlak perlu dengan banyak alasan. Spesies yang terancam memerlukan habitat untuk bertahan hidup dan tidak punah. Menikmati suasana hutan belantara menjadi sensasi yang memperkaya dan mengangkat rob manusia untuk keluar dari diri sendiri dan bersatu dengan alam. Lingkungan alam yang tidak dieksploitasi dan tidak disentuh tangan manusia entah samudera luas entah hutan-bujan atau padang gurun, menuajikkan misteri terdalam dari bumi inj yang terus-menerus memanggil manusia untuk semakin 
masuk dalam kesatuan dengan bumi dan Allah Penciptanya. Fransiskus, santo segala zaman, sungguh amat penting bagi zaman sekarang dan memang tepatlah memilihnya sebagai pelindung para ekologist. ${ }^{\text {to }}$

Dalam upaya membangun kepedulian ekologi di zaman sekarang ini Hans Küng juga mengingatkan pentingnya wawasan yang menyeluruh demi tereiptanya keutuhan semua eiptaan dan kelestarian alam. Kita harus peduli ekologi yang bukan hanya memperjuangkan kebebasan tetapi terlebih keadilan, bukan hanya mewujudkan hidup berdampingan tetaji terlebih perdamaian. bukan hānya mengangkat kesetaraan tetapi juga kemajenukan, bukan hamya membangum persaudaraan tetapi juga persaudarian. bukan hanya mengembangkan toleransi tetapi jugá ekumenisme, dan bukan hanya meningkatkan produktivitas tetapi juga solidaritas terhadap lingkungan. ${ }^{20}$

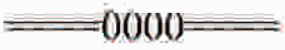

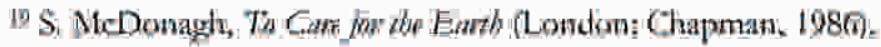

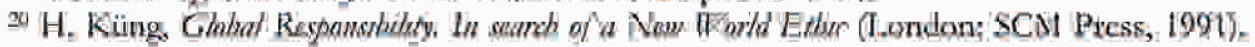

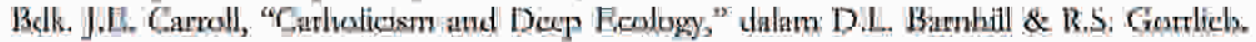

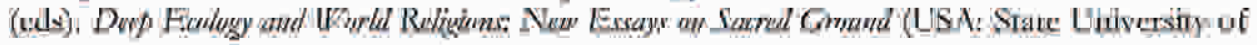

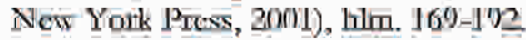




\section{DAFTAR PUSTAKA}

Bonaventura. Legenda Maiar (Wahyosudibyo, Y. (penerj). Riwayat Hidup St. Fransiskus: Kisah Besar). Jakarta: Sekafi, 1990.

Carroli J.E. "Catholicism and Deep Ecology." dalam D.L. Bamhill \& R.S. Goutlieb. (eds): Deep Ecology and World Religions: New Essays on Sacted Ground. USA: State Universify of New York Press, 2001, hlm 169-192.

Celano, Th. (Wahjasudibja, J. (penerj). St. Fransiskus dari Asisi. Riwaya Hidup yang Pertama dan Riwayat Hidup yang Kectua (Sebagian)) J Jakarta: Sekafi, 1981.

Chang, W', Jiwa Kosmis Fransiskus dari Assisi. Ende: Nusa Indali 1989. Moral Lingkungan Hidup; Yogyakarta: Kanisius 2001.

das Neves, M.C. Francesco profeta di pace e di ecologia. Padova: Messaggero, 1993.

Delio, 1. A Franciscan View of Creation. Learning to Live in a Sacramental World. The Franciscan Heritage Series 2 Bonaventure. New York: The Franciscan Institute, 2003.

Dister, N.S. "Santo Fransiskus Asisi dan Hubungannya dengan Perhatian Modern untuk Ekologi," dalam Perantau Thn. XIV No.3 (1991), hlm. $75-83$.

Groenen, C., "Ekologi Modern dalam Terang Lampu Sorot Alkitab," dalam Peraman 14, 1991.

Harun. M. "Allah. Manusia dan Alam Terintegrasî dalam Fransiskus Asisi," dalam Rohani Thn. XLIV No.2 (199.7), hlm. 41-47.

Küng, H. Global Responsibility. In search of a New World Ethic. London: SCM Press, 1991. 
Ladjar, L.L. (penerị), Fransiskus Assisi, Karya-karyanya. Yogyakarta: Kanisius, 1988.

Marpaung, M.C. Spiritualitas Dasar Fransiskam. Medan: Bina Media Perintis, 2018.

McDonagh, S. To Care for the Earth. London: Chapman, 1986.

Neves, M.C. des Francesco. prufeta di pace e di ecólogia. Padova: Messaggero, 1993.

Sherley-Price, L. The Little Flowers of Saint Francis with Five Cansiderations an the Sacved Stigmata (Terjemahan, Fiaretti dan Lima Renungan tentang Stigmata Suci. Jakarta: Sekafi, 1999).

Sidin. \$.O. "Kidung Saudara Matahari. Problematik Kata "cun' dan "per'," dalam Percutcu Thn. XJV No.4 ( L991), hlm. 103-I 12. 